\title{
A Holistic Approach to Human-Canine Synergy in Education
}

\author{
Theo Koutsopoulos ${ }^{1}$ and KC Koutsopoulos ${ }^{2 *}$ \\ ${ }^{1}$ American Community School, Greece \\ ${ }^{2}$ National Technical University, Greece
}

Submission: April 06, 2018; Published: May 30, 2018

*Corresponding author: KC Koutsopoulos, National Technical University, 10853 E. Portobello Av. Mesa AZ, 85212, Greece,

Email: koutsop@survey.ntua.gr

\begin{abstract}
This paper presents the innovative thesis of a holistic behavioural human-canine synergy in education. It is suggested that in utilizing dogs in the classroom, based exclusively either on the traditional interactional concept (i.e., provide emotional stabilization to students and increases their social interaction) or the much heralded present approach defined as the relational a concept (i.e., aid students in specific tasks in the classroom), is now absolute and a new approach, the bonding concept (i.e., becoming the instructional behavioural vehicle in applying the curriculum contents to most curriculum subjects) is necessary. All three concepts, individually or in combination and sometimes simultaneously, are involved in determining the nature, form and focus of the human-canine synergy. An approach based on this thesis, named Dogs in Learning (DiL) program, has been and still is successfully used in teaching the curriculum contents of the K-5 levels at the ACS Athens School, resulting in an extremely effective, efficient and mainly meaningful and fun to all involved educational experience.
\end{abstract}

Keywords: Human-dog synergy; Integrated approach; Dogs in learning

\section{Introduction}

In this century, important changes have taken place in the way we view the human-canine synergy (HCS) in general and in education. The term HCS has been coined for use in this paper to highlight its holistic nature and its differentiation from unidimensional terms such as humancanine interaction, relationship and bonding. The reason is that such a conceptualization leads us towards a new approach in considering the role and use of dogs in education, which is the objective of this position paper.

The importance of animals and in particular dogs in children's lives and education is well recognized [1,2] and educators have been energetically utilized them to engage students' interest and attention [3]. Hummel \& Randler [4] cite as conventional wisdom that the inclusion of living animals (compared to photos or videos of animals), particularly in science education, motivates and fosters deeper learning. Actually, the involvement of animals in general and dogs in particular in the classroom has become commonplace in the USA, Europe and the rest of the developed nations. Any more in any preschool or elementary classroom, one is likely to see live animals, mainly dogs, incorporated into lessons and activities in achieving educational objectives. In fact, in most progressive educational institutions it is probably more challenging to find educational approaches that do not include dogs or some other animals [5]. The popularity of such activities in the classroom is evident in the numerous publications for teachers on how to involve live animals into curricula [6]

It is remarkable, however, that despite such changes in education, there is an adherence of all involved in using dogs in the classroom to a unidimensional approach to humancanine synergy, by ignoring the changing nature and rationality of that affiliation, which has emerged as knowledge of new forms of canine capabilities is now available. In education today, academics, teachers, school administrators and journal editors as well as dog owners, trainers, breeders, and human society attendants, consider canines as capable of providing, in a unidimensional manner, either emotional, psychological and physical interactions to humans (i.e., affection and comfort to students and helping people to care about others) or the skill to build relationships that assist and help improve the quality of life of humans as well as the capacity to act as assistants in many human activities (i.e., dogs assisting students in their school life, police in searches, first respondents in rescues, etc.). However, we suggest and substantiate the notion that canines are in addition capable of being a powerful and effective bonding 
behavioural vehicle in facilitating or inspiring human activities (i.e., students to learn math and adults to deal with resilience issues).

In addition, there is a lack of understanding, hindering the full utilization of the various canine capabilities, that most times these dog abilities need to be combined and used simultaneously, which cannot be dealt with unless we accept the fact that they represent different manifestations of "a whole", the dialectic entity of human-canine synergy. An entity that consists of the elements of: interaction, relationship and bonding.

\section{The Human-Canine Synergy}

The human-canine synergy as a mutually beneficial and dynamic affiliation of humans and dogs has been the focus of the scientific community for many years $[7,8]$. However, the literature treatment of the issue (simplified and unidimensional) does not fully provide a comprehensive understanding of the human-canine synergy, which is possible only through an examination of the nature of the concepts involved, which in turn determine how we perceive human-canine synergy and in turn how we practice it.

\section{The human-canine interaction concept}

Animals have been used for centuries to enhance human health. As early as 1792 in England a neurological clinic (actually an asylum) introduced caring for animals as a therapeutic approach to assist patients with psychological, anxiety and stress problems [9]. A few years later, a nurse observed that when small animals were used as therapeutic companions for patients suffering from long-term chronic cases, their health would improve [10]. After WWII, the American Red Cross at the Pawling Air Force Convalescent Center in New York discovered that veterans associating with dogs were less stressed and more relaxed [11]. In education the use of animals and especially dogs have been constantly increasing their presence in the classroom $[5,12,13]$, providing emotional and behavioral stability $[6,14,15]$, empathy [16], social functioning [14], interpersonal skills [17], social communication and stereotyped or challenging behavior [18], stress release, opportunities for social interaction [19] and reading ability and skills [20-22].

The literature firmly establishes what is called in this paper as the concept of human-canine interaction, which describes a process whereby a dog is trained to provide psychological support to people in various institutions or at home and can be used in Animal-Assisted Therapy (to achieve a specific goal) [23], as well as in Animal-Assisted Activities (to provide a more open-ended, spontaneous interaction) [24]. As a result, the interaction between humans and canines is related to a therapeutic framework where canines provide affection and comfort to humans. In this way, the practice of the human-canine interaction is a simple process, creating a passive role for the canines in the human-canine synergy.

\section{The human-canine relationship concept}

The synergy of humans and canines, in the form of dogs aiding men for their subsistence and survival, as well as in every day chores started in the hunter-gatherer era and is still operating. In modern times, this form of synergy was reinvented during the First World War, when the German army relied heavily on the use of German shepherds as ambulance and messenger dogs and reached prominence after World War II with the use of guide dogs for the veterans in the United States. Nowadays canines perform many roles for humans, the most common of which are: hunting, herding, pulling loads, protecting, guiding, guarding and assisting police and military. In education canines help students in various ways. For example, Gee et al. [25] substantiated that the use of dogs in the classroom increases the speed and accuracy of students' motor skill, while Koutsopoulos et al. [26] have shown that dogs can help student perform many educational tasks inside and outside the classroom.

In sum, the term human-canine relationship describes the process whereby a dog is trained to help humans in their various activities. More specifically, it can be used as Assistance/Service dog (to perform specific tasks in aiding or assisting humans) or as Working dog (to act as assistants in many human activities). As a result, the interrelationship between humans and canines is focused on dogs assisting or working for humans, where canines perform various tasks or assist humans in various activities. In this way, the practice of the human-canine relationship is a composite process, which requires canines to have an active role in the human-canine cohabitation.

\section{The human-canine bonding concept}

The term human-animal bonding was first introduced by Leo K. Bustad in a 1983 lecture. However, its use was misleading because he advocated pet therapy and the principle of imprinting, the founding elements of the human-animal interaction and human-animal relationship [27]. It was the work of Birbil et al. [28] and Koutsopoulos et al. [26], which clarified its nature and firmly established the bonding concept as an inseparable part of the HCS. In addition, the literature has proven that companion animals in the classroom have been found to influence children's development positively [29,30], as well as demonstrate positive benefits across the lifespan $[12,24]$, and at the same time they can provide adherence to instruction and memory tasks $[26,5]$, the ability to follow instructions [31], the categorization and object recognition [32], and mainly becoming the instructional behavioural vehicle in applying the curriculum contents to most curriculum subjects [26,33].

The term human-canine bonding is describing the process whereby a dog is trained to accommodate humans in fulfilling personal or social needs. More specifically, they can be used as classroom dogs, resilience facilitators, social developers, etc. As a result, the affiliation between humans and canines is focused on facilitating human activities or inspiring humans by becoming 
a tool in achieving alternative/nontraditional approaches in accomplishing human goals. In this way, the practice of the human-canine relationship is a sophisticated process, which molds canines into playing a determining role in the humancanine cohabitation.

\section{The holistic nature of HCS}

A careful review of the literature indicates that there are two contradicting characteristics present: the first one is related to their interdisciplinary nature, which is the result of the scientific community's effort to address HCS by correlating research from the humanities, social studies, natural sciences and medicine (mainly psychology). The second characteristic is their unidimensional approach, which has resulted from the research paradigm they have been following, dictating that canines are only capable of exclusively providing either interaction activities or relationship skills, contradicting the integrating nature necessary in the holistic approach of the first characteristic.

It is our strong belief that today's unidimensional approach to HCS is no longer acceptable. It is suggested that in the holistic framework, the integration mechanism is necessary. HCS can be simultaneously instructional (i.e., achieve aspects of empathy), relational (i.e., participate in specific tasks aiding humans) and bonding (i.e., attain educational or other goals), in dialectic harmony and respecting all aspects of human-animal synergy. A holistic approach, whose intensity and necessity are not exclusive to any of their capabilities and its nature, is determined by the combination of the elements of all forms of canine capabilities. Such an approach it is not a matter of choice, but imperative in successfully utilizing dogs, especially in the classroom.

\section{Applying the Integrated Human Canine Synergy The DiL Program}

All the aspects of the human-canine synergy concepts, presented previously have been successfully applied in the Dogs in Learning program, an integral part of the ACS Athens school curriculum since 2011. The Dogs in Learning (DiL) is a program whose value and necessity are beyond the known types of dog utilization in schools. It introduces the classroom dog that is capable of being an efficient and effective tool in supporting all aspects of the human-canine synergy. Its application provides the students of the K 0-5 levels Psychological, Social, Emotional and Academic benefits, utilizing all aspects of HCS (interaction, relationship and bonding). A limited example (Bonding Applications in Teaching Mathematics) of the use of dogs in teaching mathematics is provided in Table 1

Table 1: Bonding applications in teaching mathematics (Source: ACS Athens).

\begin{tabular}{|c|c|c|}
\hline Grade & Curriculum & DiL activities \\
\hline $1^{\text {st }}$ & $\begin{array}{l}\text { Students will work with 2-dimensional and } \\
\text { 3-dimensional shapes to create new composite } \\
\text { shape. (rectangles, square, trapezoid, } \\
\text { triangles, half-circles, quarter circles) }\end{array}$ & $\begin{array}{c}\text { Students walk the dog around the obstacle course and are asked to determine } \\
\text { the shape of each obstacle (table/door=rectangle, wheel=circle, A-shape } \\
\text { obstacle=triangle etc.). Each team created is assigned a specific obstacle and using } \\
\text { a string divide the respective circle into two and four equal parts }\end{array}$ \\
\hline $2^{\text {nd }}$ & $\begin{array}{l}\text { Students will describe or create shares using } \\
\text { the works of "half of, three-thirds, four-fourths. }\end{array}$ & $\begin{array}{l}\text { In the soccer field four students are situated in the corners of an imaginary square } \\
\text { and they give the dog the command «come «from one student to the other. All the } \\
\text { students are asked to describe the shape the dog has produced (whole rectangle). } \\
\text { Then four more students are situated in the middle of the distance between } \\
\text { two other original students. Two original students and two new ones repeat the } \\
\text { exercise and the students have to describe the shape produced by the dog in terms } \\
\text { of halves. A new student is situated in the middle of the imaginary rectangular } \\
\text { and the exercise is repeated by teams of students comprised by: the student in the } \\
\text { center, two students in the middle distances and one of the original students and } \\
\text { the students have to describe the shape produced by the dog in terms of fourths }\end{array}$ \\
\hline $3^{\text {rd }}$ & $\begin{array}{l}\text { Students will solve real } \\
\text { Life mathematical } \\
\text { problems involving } \\
\text { partitioning shapes into } \\
\text { Parts with equal areas. }\end{array}$ & $\begin{array}{l}\text { In the obstacle course students are asked the following: } \\
\text { If the door opening and the wheel opening become half the original size in the } \\
\text { respective obstacles, can the dog Jump through? } \\
\text { If yes, students have to express the opening size as fraction of the original. } \\
\text { If the door opening and the wheel opening becomes one quarter of the original size } \\
\text { can the dog go through? } \\
\text { If yes, students have to express the opening size as a fraction of the original }\end{array}$ \\
\hline $4^{\text {th }}$ & $\begin{array}{l}\text { Students will record the } \\
\text { Results of comparisons } \\
\text { with symbols }>,=, \text { or }< \\
\text { and justify the conclusions. }\end{array}$ & $\begin{array}{l}\text { Student divided into three teams. Each team races against the dog and the time is } \\
\text { recorded (the first student to finish). } \\
\text { Then the dog runs by itself. } \\
\text { Each student is asked to compare } \\
\text { the four numbers and express } \\
\text { their conclusions in terms of: } \\
>,=\text {, or }<\end{array}$ \\
\hline
\end{tabular}




\section{Psychology and Behavioral Science International Journal}

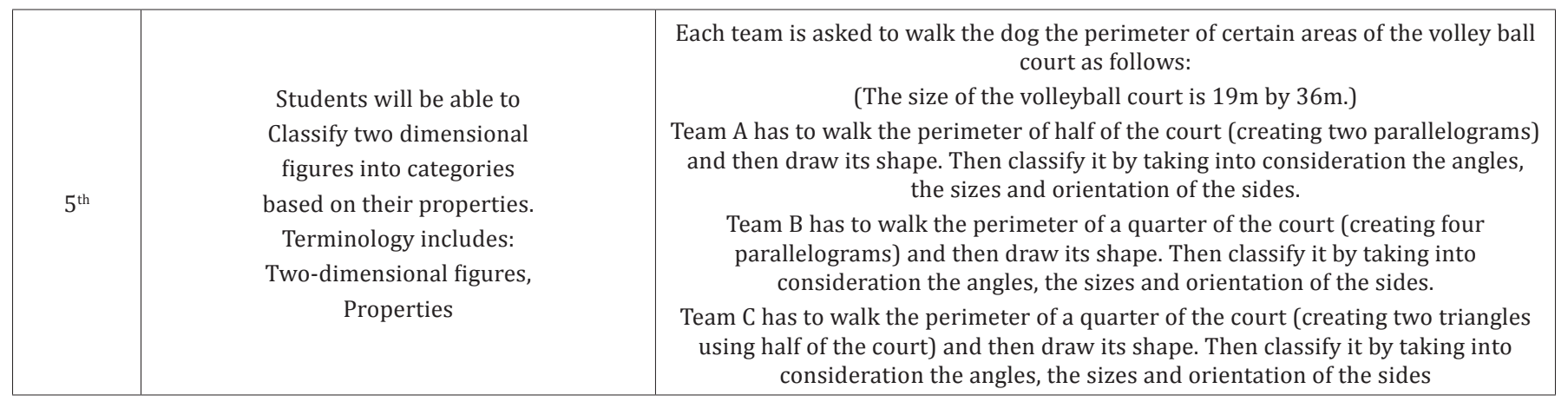

\section{Conclusion}

The concept of a holistic HCS represents a new innovative approach to teaching and learning using trained dogs, by providing an effective playful and enjoyable manner: the psychological support of the HCS interaction concept (i.e., provide emotional stabilization to students and increases their social interaction); the assistance skills of the HCS relationship concept (i.e., aid students in specific tasks in the classroom); and the instructional capabilities of the HCS bonding concept (i.e., becoming the instructional behavioural vehicle in applying the curriculum contents to most curriculum subjects).

As for the contributions of the presented holistic HCS these are: First, is the abandonment of the literature's interchangeable use of the terms: human-canine interaction, human-canine relationship and human-canine bonding, which lead to redefining them and putting them within a holistic perspective. Indeed, even a cursory review of the literature shows that these terms up to now were differentiated by researchers only in terms of different animal contexts [34]. For example, those working with agricultural animals use the term human-animal relationship, while those concerned with companion animals use the term human-animal bonding to present the sane role of the animal. Within the framework of the holistic HCS, these terms represent the form and intensity of a HCS state that determines its nature and practicing approach.

Second, the proposed HCS concept unambiguously and categorically has established that a holistic concept should be at the centre of any approach towards using dogs in the classroom. This leads to the position that utilizing dogs in the classroom, based exclusively either on the traditional interactional approach or the much heralded present approach defined as the relational approach, is now absolute for the following reasons: a new approach, the bonding concept, is necessary (facilitating or inspiring human activities); all three concepts mentioned previously are involved in determining the nature, form and focus of the human-canine synergy; and there is a fundamental aspect of the holistic human-canine synergy, namely the necessary integration, whereby any form of dog activity does not exclude another, but each one can be part of any effort and even they can be used simultaneously. Third, the DiL program at ACS Athens has shown that it successfully provides its benefits by basing its operation upon the same academic curriculum and having the same educational objectives as those applied by the school. The Dogs in learning program is simply an alternative teaching approach characterized by fun and joy, but its educational goals remain those of the school and are focused on enriching and enhancing student learning in a variety of subject areas.

Finally, the HCS by its nature cannot be confined into a simple unidimensional psychological, behavioral, emotional, physiological or even social approach to address the increasing popularity of human canine cohabitation. We believe that HCS is all of them and probably more. But as animal assisted interventions in schools and elsewhere is growing, scientific research is needed to measure its exact impact and to explain the physiological the various and complicate mechanisms involved.

\section{Authors' Contribution}

Author A' developed the concept and its application. Author $B$ helped its formulation and the writing of the paper. Both authors read and approved the final manuscript.

\section{References}

1. Beck AM (2011) Animals and child health and development. In: Mc Cardle P, Mc Cune S, Griffin JA, Esposito L, Freund LS (Eds.), Animals in our lives: Human-animal interaction in family, community and therapeutic settings. Baltimore, Maryland, USA.

2. Melson GF, Schwartz RL, Beck AM (1997) The importance of companion animals in children's lives: Implications for veterinary practice. J Am Vet Med Assoc 211(12): 1512-1518.

3. Gee NR, Fine AH, Mc Cardle P (2017) How animals help students learn: Research and practice for educators and mental-health professionals. Taylor \& Francis, Routledge, New York, USA.

4. Hummel E, Randler C (2012) Living animals in the classroom: A metaanalysis on learning outcome and a treatment-control study focusing on knowledge and motivation. Journal of Science Education and Technology 21(1): 95-105.

5. Gee N, Fine A, Mc Cardle P (2017) How animals help students learn: Research and practice for educators and mental health professionals. New York, Routledge, USA.

6. Anderson KL, Olson MR (2006) The value of a dog in a classroom of children with severe emotional disorders. Journal of Anthrozoös 19(1): 35-49.

7. Levinson MB (1972) Pets and human development.

8. Levinson MB (1979) Pet-oriented child psychotherapy. University of Michigan Press, Ann Arbor, USA. 
9. Bustad KL (1998) Animals, aging, and the aged. University of Minnesota Press, Minneapolis, USA.

10. Nightingale F (1860) Notes on nursing: what it is, and what it is not. Appleton and company, New York, USA.

11. Mc Cardle P (2010) Animals in our lives. Human-animal interaction. In: Griffin J, Esposito L, Freund L (Eds.), Family, community \& therapeutic settings. Pacific Grove, Brooks Cole, California, USA.

12. Endenburg N, Van Lith HA (2010) The influence of animals on the development of children. Vet J 190(2): 208-214.

13. Serpell J (1991) Beneficial effects if pet ownership on some aspects of human health and behaviour. J R Soc Med 84(12): 717-720.

14. Brelsford LV, Mints K, Gee RN, Pfeffer K (2017) Animal-assisted interventions in the classroom. A Syst Rev Inter J Environ Res Pub Hea 14(7): 669-702.

15. Stefanini MC, Martino A, Bacci B, Tani F (2016) The effect of animalassisted therapy on emotional and behavioural symptoms in children and adolescents hospitalized for acute mental disorders. European Journal of Integrative Medicine 8(2): 81-88.

16. Tissen I, Hergovich A, Spiel C (2007) School-based social training with and without dogs: Evaluation of their effectiveness. Journal of Anthrozoös 20: 365-373.

17. O Haire ME, Mc Kenzie SJ, Mc Cune S, Slaughter V (2013) Effects of animal-assisted activities with guinea pigs in the primary school classroom. Journal of Anthrozoös 26(3): 3-8.

18. Davies TN, Scalzo R, Butler E, Stauffer M, Farah YN (2015) Animalassisted interventions for children with Autism Spectrum Disorder: A systematic review. Education and Training in Autism and Developmental Disabilities 50(3): 316-329.

19. Beetz A (2013) Socio-emotional correlates of a school-dog-teacher team in the classroom. Front Psycholo 4: 886-493.

20. Bassette LA, Taber-Doughty $\mathrm{T}$ (2013) The effects of a dog reading visitation program on academic engagement behavior in three elementary students with emotional and behavioral disabilities: A single case study. Child Youth Care Forum 42(3): 239-256.

21. Kirnan J, Siminerio S, Wong Z (2016) The impact of a therapy dog program on skills and attitudes towards reading. Early Childhood Education Journal 44(6): 637-651.
22. Le Roux MC, Swartz L, Swart E (2014) The effect of an animal-assisted reading program on the reading rate, accuracy and comprehension of grade 3 students: A randomized control study. Child Youth Care 43(6): 655-673.

23. Brodie JS, Biley CF (1998) An exploration of the potential benefits of pet-facilitated therapy. Journal of Clinical Nursing 8(4): 329-337.

24. Fine HA (2008) Handbook on animal-assisted therapy: theoretical foundations and guidelines. New York, USA.

25. Gee NR, Harris SL, Johnson KL (2007) The role of therapy dogs in speed and accuracy to complete motor skills tasks for preschool children. J Anthrozoös 20(4): 375-386.

26. Koutsopoulos CK, Gialamas S, Koutsopoulos T (2016) A true manifestation of GMP: Dogs in Learning. In Avgerinoy M, Gialamas S (Eds.), Revolutionizing K-12 Blended Learning through the i2 Flex Classroom Model. IGI Global, Pennsylvania, Hershey, USA.

27. Brown E (2011) Self-psychology and the human-animal bond: An overview. In: Blazina C, Boyraz G, Shen-Miller D (Eds.), The psychology of the human-animal bond, pp. 137-149.

28. Birbil C, Koutsopoulos T, Makropoulos C, Sax A, Gialamas S (2015) Dogs in learning: Transforming education. Inter J Elemen Edu 4(2): 16-24.

29. Hergovich A, Monshi B, Semmler G, Zieglmayer V (2002) The effects of the presence of a dog in the classroom. Anthrozoös 15(1): 37-50.

30. Gee NR, Crist EN, Carr DN (2012) Preschool children require fewer instructional prompts to perform a memory task in the presence of a dog. Anthrozoös 23(2): 173-184.

31. Gee NR, Sherlock TR, Bennett EA, Harris SL (2009) Pre-schoolers adherence to instructions as a function of presence of a dog and motor skills task. Anthrozoös 22(3): 267-276.

32. Gee NR, Church MT, Altobelli CL (2010) Pre-schoolers make fewer errors on an object categorization task in the presence of a dog. Anthrozoös 23(3): 223-230.

33. Koutsopoulos T, Koutsopoulos CK (2018) Dogs in learning: An implementation of human-canine synergy in education. J Edu Soc and Behav Sci 25(2): 1-12.

34. Hosey G, Melf V (2014) Human-animal interactions, relationships and bonds: a review and analysis of the literature. Inter J Comp Psych 27(1): 117-142.

\section{Your next submission with Juniper Publishers will reach you the below assets}

- Quality Editorial service

- Swift Peer Review

- Reprints availability

- E-prints Service

- Manuscript Podcast for convenient understanding

- Global attainment for your research

- Manuscript accessibility in different formats

( Pdf, E-pub, Full Text, Audio)

- Unceasing customer service

Track the below URL for one-step submission https://juniperpublishers.com/online-submission.php 